\title{
Association of tumor necrosis factor- $\alpha$ polymorphism with chemotherapy-induced oral mucositis in patients with esophageal cancer
}

\author{
KAZUHIKO SAKAMOTO $^{1}{ }^{\text {, SHIGERU TAKEDA }}{ }^{1}$, SHINSUKE KANEKIYO ${ }^{1}$, MITSUO NISHIYAMA ${ }^{1}$, \\ MASAHIRO KITAHARA ${ }^{1}$, TOMIO UENO ${ }^{1}$, SHIGERU YAMAMOTO ${ }^{1}$, SHIGEFUMI YOSHINO ${ }^{2}$, \\ SHOICHI HAZAMA ${ }^{3}$, NAOKO OKAYAMA ${ }^{4}$ and HIROAKI NAGANO ${ }^{1}$

\begin{abstract}
${ }^{1}$ Department of Gastroenterological, Breast and Endocrine Surgery, Yamaguchi University Graduate School of Medicine; ${ }^{2}$ Oncology Center, Yamaguchi University Hospital; ${ }^{3}$ Department of Translational Research and Developmental Therapeutics against Cancer, Yamaguchi University School of Medicine;

${ }^{4}$ Division of Laboratory, Yamaguchi University Hospital, Ube, Yamaguchi 755-8505, Japan
\end{abstract}

Received June 8, 2016; Accepted September 2, 2016

DOI: $10.3892 / \mathrm{mco} .2016 .1081$

\begin{abstract}
The purpose of this study was to evaluate the association between tumor necrosis factor (TNF)- $\alpha$ polymorphisms and oral mucositis (OM) from 5-fluorouracil (5-FU) plus cisplatin (CDDP) chemotherapy for esophageal cancer. The rs1799964 polymorphism of TNF- $\alpha$ was genotyped using the tetra-primer amplification refractory mutation system polymerase chain reaction. The experimental group comprised 64 patients who received chemotherapy for esophageal cancer between 1997 and 2004; a total of 106 patients between 2005 and 2013 were investigated as the validation group. Univariate analysis of the experimental group revealed that the TT genotype of TNF- $\alpha$ rs1799964 was significantly higher in patients with grade 1-4 OM compared with the TC/CC genotypes [univariate odds ratio $(\mathrm{OR})=4.0 ; \mathrm{P}=0.029]$. Similarly, univariate analysis of the validation group revealed that the percentage of the TT genotype was significantly higher in patients with grade 1-4 OM compared with the TC/CC genotypes ( $\mathrm{OR}=2.8 ; \mathrm{P}=0.043)$. This difference in risk was replicated in the validation cohort. Thus, the TT genotype of TNF- $\alpha$ rs1799964 may be a predictor of chemotherapy-induced $\mathrm{OM}$ in patients with esophageal cancer.
\end{abstract}

\section{Introduction}

Chemotherapy significantly improves the clinical outcome of patients with esophageal cancer. Preoperative chemotherapy may be considered as standard treatment for patients with

Correspondence to: Dr Kazuhiko Sakamoto, Department of Gastroenterological, Breast and Endocrine Surgery, Yamaguchi University Graduate School of Medicine, 1-1-1 Minami-Kogushi, Ube, Yamaguchi 755-8505, Japan

E-mail: kazusaka@yamaguchi-u.ac.jp

Key words: polymorphism, chemotherapy, oral mucositis clinical stage II or III esophageal cancer (1). Furthermore, chemoradiotherapy for esophageal cancer has been established as a treatment for stage I disease, as well as for advanced cases $(2,3)$. The combination of 5-fluorouracil (5-FU) plus cisplatin (CDDP) is currently the standard chemotherapy for esophageal cancer. Although chemotherapy for esophageal cancer using 5-FU plus CDDP has become a widely applied treatment, chemotherapy-induced oral mucositis (OM) has been reported to complicate the course in $\leq 40 \%$ of patients receiving an 5-FU-based regimen $(4,5)$. The discomfort and pain associated with OM may impair oral intake of fluids and calories, resulting in anorexia, cachexia, dehydration and overt malnutrition (6). Nishimura et al reported that the incidence of grade $\geq 1 \mathrm{OM}$ according to the National Cancer Institute Common Terminology Criteria for Adverse Events, version 3 (NCI-CTCAE 3.0; https://ctep.cancer.gov/protocolDevelopment/electronic_applications/docs/ctcaev3.pdf), was the highest during chemotherapy for esophageal cancer (57.8\%) (7). Predicting toxicities prior to chemotherapy is crucial for treatment selection. We previously reported that the TNF- $\alpha$ rs1799964 polymorphism was associated with susceptibility to $\mathrm{OM}$ in patients treated with 5-FU plus CDDP for gastrointestinal malignancies (8). Currently, 5-FU plus CDDP chemotherapy is mainly performed for esophageal cancer. In order to validate the reliability of our previous report, we investigated the association between TNF- $\alpha$ rs1799964 and chemotherapy-induced OM in esophageal cancer patients.

\section{Patients and methods}

Patients. This was a retrospective cohort study that included patients treated for esophageal cancer between 1997 and 2013. The participants comprised 170 consecutive Japanese patients (152 men and 18 women) with esophageal cancer who underwent chemotherapy at the Department of Gastroenterological, Breast and Endocrine Surgery of the Yamaguchi University Graduate School of Medicine (Ube, Japan). The experimental group comprised 64 patients between 1997 and 2004, who 
were reported in our previous article (8). The validation group comprised 106 patients who underwent chemotherapy between 2005 and 2013. Chemotherapy was performed as preoperative or postoperative treatment, or for progressive (unresectable) cases.

Chemotherapy. Chemotherapy was combined with radiotherapy to increase effectiveness for cases with progressive disease. Since patients with esophageal cancer who received preoperative chemotherapy exhibited superior overall survival compared with those who received postoperative chemotherapy in the Japan Clinical Oncology Group (JCOG) trial 9907, as was reported at the American Society of Clinical Oncology Annual Meeting in 2008 (1), preoperative chemotherapy was introduced from 2008 onwards. Up to 2007, a low-dose 5-FU plus CDDP chemotherapy regimen had been used, which consisted of 5-FU at a concentration of $330 \mathrm{mg} / \mathrm{m}^{2}$ administered by continuous intravenous infusion on days 1-7, and CDDP at a concentration of $6 \mathrm{mg} / \mathrm{m}^{2}$ administered intravenously for $2 \mathrm{~h}$ by drip infusion on days 1-5. This regimen was repeated for 4 weeks. In addition, the regimen of 5-FU plus CDDP chemotherapy reported in JCOG9907 was also used, which included standard-dose 5-FU plus CDDP chemotherapy, consisting of 5-FU at $800 \mathrm{mg} / \mathrm{m}^{2}$ administered by continuous intravenous infusion on days $1-5$ and CDDP at $80 \mathrm{mg} / \mathrm{m}^{2}$ administered intravenously for $2 \mathrm{~h}$ by drip infusion on day 1 . This regimen was repeated twice every 3 weeks. If radiation was used in combination with chemotherapy, the doses of 5-FU $\left(700 \mathrm{mg} / \mathrm{m}^{2}\right)$ and CDDP $\left(70 \mathrm{mg} / \mathrm{m}^{2}\right)$ were reduced (2). NCI-CTCAE 3.0 was used to evaluate chemotherapy-induced OM. Toxicity was evaluated when symptoms of the highest-grade OM appeared.

DNA specimens and genotyping. For DNA analysis, 7-ml samples of peripheral blood were obtained from all the patients. DNA was isolated by a conventional NaI method and stored at $4^{\circ} \mathrm{C}(9)$. All polymorphisms were identified with the tetra-primer amplification refractory mutation system polymerase chain reaction (PCR); the details of the primers and PCR conditions were previously described (10-12).

Statistical analysis. Continuous data were expressed as median and range and were analyzed using the Mann-Whitney U test. Categorical data were analyzed using the $\chi^{2}$ test or Fisher's exact test. Differences in genotype frequency were analyzed using the $\chi^{2}$ test or Fisher's exact test of independence, with which each of the genotype frequencies was evaluated to determine whether it was consistent with expected Hardy-Weinberg proportions. As there were too few homozygotes for the rare allele to perform a $2 \times 3 \chi^{2}$ test or Fisher's exact test, homozygotes of the dominant alleles and variant carriers were compared by a $2 \times 2$ test. Odds ratios (OR) and $95 \%$ confidence intervals (CI) were also calculated. A P-value of $<0.05$ was considered to indicate statistically significant differences. All statistical calculations were performed with the IBM SPSS Statistics version 22.0 software package (IBM Japan Inc., Tokyo, Japan).

\section{Results}

Patient characteristics. The patient characteristics of the experimental and the validation groups are summarized in
Table I. The percentage of patients receiving postoperative adjuvant chemotherapy was significantly lower in the validation group compared with that in the experimental group $(\mathrm{P}<0.01)$. There was a significant difference between the experimental and validation groups regarding the chemotherapy regimen. The distribution of TNF- $\alpha$ genotypes was similar between the two groups (rs1799964; experimental group: TT $68.8 \%$, CT $25.0 \%$ and CC $6.2 \%$; validation group: TT $73.6 \%$, CT $24.5 \%$ and $\mathrm{CC} 1.9 \%$ ). The incidence of grade $1-4 \mathrm{OM}$ in the experimental and validation groups was 40.6 and $37.7 \%$, respectively. Although the treatment regimen was changed from low-dose 5-FU plus CDDP to standard-dose 5-FU plus CDDP from 2008 onwards, there were no differences in the frequency of OM between the two treatments (grade 1-4 OM: low dose, $42.5 \%$ vs. standard dose, $35.6 \%, \mathrm{P}=0.35$ ).

Association between patient characteristics and OM. The associations between patient characteristics and grade 1-4 of OM by univariate analysis are shown in Table II. In the experimental group, the incidence of the TT genotype of TNF- $\alpha$ rs1799964 was significantly higher among patients with grade 1-4 OM compared with patients without $\mathrm{OM}(\mathrm{OR}=4.0,95 \% \mathrm{CI}=1.2-13.9$; $\mathrm{P}=0.029)$. In the validation group, the body mass index (BMI; $\mathrm{OR}=0.8,95 \% \mathrm{CI}=0.69-0.94 ; \mathrm{P}<0.01)$ and the incidence of the TT genotype of TNF- $\alpha$ rs1799964 (OR=2.8, 95\% CI=1.03-7.8; $\mathrm{P}=0.043$ ) were significantly higher in patients with grade $1-4 \mathrm{OM}$ compared with patients without OM. Radiotherapy tended to be associated with a high frequency of grade 1-4 OM $(\mathrm{P}=0.076)$. There was no significant difference in the frequency of $\mathrm{OM}$ by chemotherapy regimen. Regarding the association between the TNF- $\alpha$ allele of rs1799964 and OM, the results were similar for the experimental and validation groups.

\section{Discussion}

Our previous study demonstrated that patients with gastrointestinal malignancies who had the TT genotype of the TNF- $\alpha$ promoter gene polymorphism rs1799964 had a significantly higher risk of chemotherapy-induced OM compared with patients with other genotypes. Although several gastrointestinal malignancies were investigated in our previous study, in the present study only patients with esophageal cancer were investigated as the experimental group. We observed that the rs1799964 polymorphism of TNF- $\alpha$ was associated with chemotherapy-induced OM even in the experimental group, which only included patients with esophageal cancer. Furthermore, similar results were also demonstrated in the validation group.

TNF- $\alpha$ is a key pro-inflammatory cytokine that causes tissue damage, and release of TNF- $\alpha$ may initiate and accelerate the development of OM (13). It has been reported in several human studies that the levels of pro-inflammatory cytokines are increased in the blood and saliva of patients during cancer treatment (14-16). Other studies using animal models have shown evidence of changes in the serum level and tissue expression of nuclear factor $\kappa-\mathrm{B}$ and the pro-inflammatory cytokines [TNF- $\alpha$, interleukin (IL)-1 $\beta$ and IL-6) following administration of chemotherapeutic drugs (14,17-19). The rs1800629 polymorphism of TNF- $\alpha$ has been reported to be associated with hypercytokinemia, such as sepsis (20-22); this 
Table I. Patient characteristics.

\begin{tabular}{|c|c|c|c|}
\hline Characteristics & Experimental group $(n=64)$ & Validation group $(n=106)$ & P-value \\
\hline Age, years & $62(27-82)$ & $64(40-81)$ & 0.18 \\
\hline Gender & & & 0.15 \\
\hline Male & $60(93.8)$ & $92(86.8)$ & \\
\hline Female & $4(6.3)$ & $14(13.2)$ & \\
\hline BMI, kg/m² & $20.2(12.6-28.8)$ & $19.2(14.1-31.2)$ & 0.21 \\
\hline Purpose of chemotherapy & & & $<0.01$ \\
\hline Postoperative & $35(54.7)$ & $30(28.3)$ & \\
\hline Preoperative & $0(0.0)$ & $45(42.5)$ & \\
\hline Progression/recurrence & $29(45.3)$ & $31(29.2)$ & \\
\hline Radiotherapy & & & 0.59 \\
\hline Yes & $18(28.1)$ & $34(32.1)$ & \\
\hline No & $46(71.9)$ & $72(67.9)$ & \\
\hline Regimen of chemotherapy & & & $<0.01$ \\
\hline Low-dose FP & $64(100.0)$ & $16(15.1)$ & \\
\hline Standard-dose FP & $0(0.0)$ & $90(84.9)$ & \\
\hline Genotype of TNF- $\alpha$ rs 1799964 & & & 0.32 \\
\hline $\mathrm{TT}$ & $44(68.8)$ & $78(73.6)$ & \\
\hline $\mathrm{CT}$ & $16(25.0)$ & $26(24.5)$ & \\
\hline $\mathrm{CC}$ & $4(6.2)$ & $2(1.9)$ & \\
\hline Oral mucositis & & & 0.84 \\
\hline Grade 0 & $38(59.4)$ & $66(62.3)$ & \\
\hline Grade 1 & $12(18.7)$ & $17(16.0)$ & \\
\hline Grade 2 & $8(12.5)$ & $14(13.2)$ & \\
\hline Grade 3 & $4(6.3)$ & 8 (7.6) & \\
\hline Grade 4 & $2(3.1)$ & $1(0.9)$ & \\
\hline
\end{tabular}

Data are presented as median values (range) or as absolute numbers (\%). BMI, body mass index; FP, 5-fluorouracil plus cisplatin; TNF, tumor necrosis factor.

Table II. Asssociation between patient characteristics and grade 1-4 oral mucositis by univariate analysis in the experimental and validation groups.

\begin{tabular}{|c|c|c|c|c|c|c|}
\hline \multirow[b]{2}{*}{ Characteristics } & \multicolumn{3}{|c|}{ Experimental group $(n=64)$} & \multicolumn{3}{|c|}{ Validation group $(n=106)$} \\
\hline & OR & $95 \% \mathrm{CI}$ & P-value & OR & $95 \% \mathrm{CI}$ & P-value \\
\hline Age & 1.02 & $0.97-1.1$ & 0.49 & 0.98 & $0.93-1.03$ & 0.33 \\
\hline \multicolumn{7}{|l|}{ Gender } \\
\hline Male vs. female & 0.67 & $0.09-5.1$ & 0.7 & 0.4 & $0.13-1.3$ & 0.12 \\
\hline BMI & 1.1 & $0.9-1.3$ & 0.47 & 0.8 & $0.69-0.94$ & $<0.01$ \\
\hline \multicolumn{7}{|l|}{ Purpose of chemotherapy } \\
\hline $\begin{array}{l}\text { Postoperative vs. } \\
\text { preoperative/progression/recurrence }\end{array}$ & 1.3 & $0.45-3.4$ & 0.69 & 1.4 & $0.59-3.3$ & 0.46 \\
\hline \multicolumn{7}{|l|}{ Radiotherapy } \\
\hline Yes vs. no & 0.9 & $0.3-2.8$ & 0.86 & 2.1 & $0.92-4.9$ & 0.076 \\
\hline \multicolumn{7}{|l|}{ Regimen of chemotherapy } \\
\hline Low- vs. standard-dose FP & & & & 1.8 & $0.63-5.3$ & 0.28 \\
\hline \multicolumn{7}{|l|}{ TNF- $\alpha$ rs1799964 genotype } \\
\hline TT vs. CT+CC & 4.0 & $1.2-13.9$ & 0.029 & 2.8 & $1.03-7.8$ & 0.043 \\
\hline
\end{tabular}

OR, odds ratio; CI, confidence interval; BMI, body mass index; FP, 5-fluorouracil plus cisplatin; TNF, tumor necrosis factor. 
polymorphism was also reported to be associated with enhanced TNF- $\alpha$ transcription in vitro (23). However, the frequency of TNF- $\alpha$ rs1800629 in the Japanese population was significantly lower compared with that in Caucasians (frequency of A allele: Japanese vs. Caucasian, $1.1-1.3$ vs. 10-18\%, respectively) (24). Cui et al reported an analysis of the association between TNF- $\alpha$ rs1799964, which was the subject of the present study, and the serum concentration of TNF- $\alpha$ (25); they found that the TC and CC genotypes of rs1799964 were associated with decreased serum TNF- $\alpha$ levels. The authors also performed a functional analysis to compare the activities of the rs1799964 $\mathrm{T} / \mathrm{C}$ alleles. The gene expression of the $\mathrm{C}$ allele was significantly reduced compared with that of the T allele, which was defined as wild-type, when measured using a luciferase assay in cultured HepG2 cells. However, Higuchi et al reported that the transcriptional activity of the $\mathrm{C}$ allele of rs1799964 was twice as high as that of the dominant $\mathrm{T}$ allele in response to concanavalin A (26). There is a discrepancy between our results and the reported promoter activities of TNF- $\alpha$ rs1799964 polymorphisms. Further studies are required to confirm the association between TNF- $\alpha$ promoter polymorphism and OM.

Although it has been reported that the patient-related risk factors of chemotherapy-induced OM include age, gender, nutritional status, oral microbiota, status of oral health and hygiene, salivary secretory function and neutrophil count, there remains some controversy regarding risk factors (27). In this study, low BMI was one of the risk factors in the validation group, but it was not confirmed as a risk factor in the experimental group. Clinical practice guidelines have been drawn for the management of OM based on evidence and expert opinions (28-30). Oral care reduces the microbial load; therefore, maintenance of oral hygiene is a major factor in the prevention and mitigation of oral injury. Cryotherapy, keratinocyte growth factor-1 (palifermin), low-level laser therapy and benzydamine mouthwash are recommended as other preventive measures. Further clinical trials are required before drugs such as palifermin may be used in the general medical field, and their cost-effectiveness must also be discussed. It is considered that preventive treatments should be aggressively introduced to patients identified as being at high risk of OM prior to chemotherapy, including patients with the TT genotype of TNF- $\alpha$ rs1799964.

This study had several limitations, including its single-institution nature, the relatively small sample size, and the fact that the clinical data were collected and analyzed retrospectively. Therefore, our findings require validation in a prospective study including a larger number of patients treated at several institutions. The results of this study demonstrated that the rs1799964 polymorphism of TNF- $\alpha$ was associated with OM risk in patients with esophageal cancer treated with chemotherapy, and the result was validated in a separate cohort, suggesting that this polymorphism may be used as a predictive biomarker. Analysis of such polymorphisms may help individualize chemotherapeutic regimens to optimally treat esophageal cancer, while minimizing the risk of OM.

\section{Acknowledgements}

This study was supported by Grants-in-Aid for Scientific Research from the Ministry of Education, Science and Culture of Japan (no. 26461912).

\section{References}

1. Ando N, Kato H, Igaki H, Shinoda M, Ozawa S, Shimizu H, Nakamura T, Yabusaki H, Aoyama N, Kurita A, et al: A randomized trial comparing postoperative adjuvant chemotherapy with cisplatin and 5-fluorouracil versus preoperative chemotherapy for localized advanced squamous cell carcinoma of the thoracic esophagus (JCOG9907). Ann Surg Oncol 19: 68-74, 2012.

2. Ishida K, Ando N, Yamamoto S, Ide H and Shinoda M: Phase II study of cisplatin and 5-fluorouracil with concurrent radiotherapy in advanced squamous cell carcinoma of the esophagus: A Japan esophageal oncology group (JEOG)/Japan clinical oncology group trial (JCOG9516). Jpn J Clin Oncol 34: 615-619, 2004.

3. Kato H, Sato A, Fukuda H, Kagami Y, Udagawa H, Togo A Ando N, Tanaka O, Shinoda M, Yamana H and Ishikura S: A phase II trial of chemoradiotherapy for stage I esophageal squamous cell carcinoma: Japan clinical oncology group study (JCOG9708). Jpn J Clin Oncol 39: 638-643, 2009.

4. Loprinzi CL and Dose AM: Studies on the prevention of 5-fluorouracil-induced oral mucositis. NCI Monogr 93-94, 1990.

5. Miaskowski C: Oral complications of cancer therapies. Management of mucositis during therapy. NCI Monogr 95-98, 1990.

6. De Conno F, Ripamonti C, Sbanotto A and Ventafridda V: Oral complications in patients with advanced cancer. J Palliat Care 5: $7-15,1989$.

7. Nishimura N, Nakano K, Ueda K, Kodaira M, Yamada S, Mishima Y, Yokoyama M, Terui Y, Takahashi S and Hatake K: Prospective evaluation of incidence and severity of oral mucositis induced by conventional chemotherapy in solid tumors and malignant lymphomas. Support Care Cancer 20: 2053-2059, 2012.

8. Sakamoto K, Oka M, Yoshino S, Hazama S, Abe T, Okayama N and Hinoda Y: Relation between cytokine promoter gene polymorphism and toxicity of 5-fluorouracil plus cisplatin chemotherapy. Oncol Rep 16: 381-387, 2006.

9. Wang L, Hirayasu K, Ishizawa M and Kobayashi Y: Purification of genomic DNA from human whole blood by isopropanol-fractionation with concentrated Nal and SDS. Nucleic Acids Res 22: 1774-1775, 1994.

10. Hamajima N, Saito T, Matsuo K, Kozaki K, Takahashi T and Tajima K: Polymerase chain reaction with confronting two-pair primers for polymorphism genotyping. Jpn J Cancer Res 91: $865-868,2000$

11. Ye S, Dhillon S, Ke X, Collins AR and Day IN: An efficient procedure for genotyping single nucleotide polymorphisms. Nucleic Acids Res 29: E88-E98, 2001.

12. Okayama N, Fujimura K, Nakamura J, Suehiro Y, Hamanaka Y and Hinoda Y: Evaluation of a new efficient procedure for single-nucleotide polymorphism genotyping: Tetra-primer amplification refractory mutation system-polymerase chain reaction. Clin Chem Lab Med 42: 13-16, 2004.

13. Aggarwal BB, Kohr WJ, Hass PE, Moffat B, Spencer SA, Henzel WJ, Bringman TS, Nedwin GE, Goeddel DV and Harkins RN: Human tumor necrosis factor. Production, purification, and characterization. J Biol Chem 260: 2345-2354, 1985.

14. Logan RM, Gibson RJ, Sonis ST and Keefe DM: Nuclear factor-kappaB (NF-kappaB) and cyclooxygenase-2 (COX-2) expression in the oral mucosa following cancer chemotherapy. Oral Oncol 43: 395-401, 2007.

15. Xanthinaki A, Nicolatou-Galitis O, Athanassiadou P, Gonidi M, Kouloulias V, Sotiropoulou-Lontou A, Pissakas G, Kyprianou K, Kouvaris J and Patsouris E: Apoptotic and inflammation markers in oral mucositis in head and neck cancer patients receiving radiotherapy: Preliminary report. Support Care Cancer 16: 1025-1033,2008

16. Morales-Rojas T, Viera N, Morón-Medina A, Alvarez CJ and Alvarez A: Proinflammatory cytokines during the initial phase of oral mucositis in patients with acute lymphoblastic leukaemia. Int J Paediatr Dent 22: 191-196, 2012.

17. Logan RM, Stringer AM, Bowen JM, Gibson RJ, Sonis ST and Keefe DM: Serum levels of NFkappaB and pro-inflammatory cytokines following administration of mucotoxic drugs. Cancer Biol Ther 7: 1139-1145, 2008.

18. Logan RM, Stringer AM, Bowen JM, Gibson RJ, Sonis ST and Keefe DM: Is the pathobiology of chemotherapy-induced alimentary tract mucositis influenced by the type of mucotoxic drug administered? Cancer Chemother Pharmacol 63: 239-251, 2009. 
19. Curra M, Martins MA, Lauxen IS, Pellicioli AC, Sant'Ana Filho M, Pavesi VC, Carrard VC and Martins MD: Effect of topical chamomile on immunohistochemical levels of IL-1 $\beta$ and TNF- $\alpha$ in 5-fluorouracil-induced oral mucositis in hamsters. Cancer Chemother Pharmacol 71: 293-299, 2013.

20. Mira JP, Cariou A, Grall F, Delclaux C, Losser MR, Heshmati F, Cheval C, Monchi M, Teboul JL, Riché F, et al: Association of TNF2, a TNF-alpha promoter polymorphism, with septic shock susceptibility and mortality: A multicenter study. JAMA 282: 561-568, 1999.

21. Tang GJ, Huang SL, Yien HW, Chen WS, Chi CW, Wu CW, Lui WY, Chiu JH and Lee TY: Tumor necrosis factor gene polymorphism and septic shock in surgical infection. Crit Care Med 28: 2733-2736, 2000.

22. O'Keefe GE, Hybki DL and Munford RS: The G-->A single nucleotide polymorphism at the 308 position in the tumor necrosis factor-alpha promoter increases the risk for severe sepsis after trauma. J Trauma 52: 816-825, 2002.

23. Brinkman BM, Zuijdeest D, Kaijzel EL, Breedveld FC and Verweij CL: Relevance of the tumor necrosis factor alpha (TNF alpha) 308 promoter polymorphism in TNF alpha gene regulation. J Inflamm 46: 32-41, 1995.

24. Nakada TA, Hirasawa H, Oda S, Shiga H, Matsuda K, Nakamura M, Watanabe E, Abe R, Hatano M and Tokuhisa T: Influence of toll-like receptor 4, CD14, tumor necrosis factor, and interleukine-10 gene polymorphisms on clinical outcome in Japanese critically ill patients. J Surg Res 129: 322-328, 2005.
25. Cui G, Wang H, Li R, Zhang L, Li Z, Wang Y, Hui R, Ding H and Wang DW: Polymorphism of tumor necrosis factor alpha (TNF-alpha) gene promoter, circulating TNF-alpha level, and cardiovascular risk factor for ischemic stroke. J Neuroinflammation 9: 235, 2012.

26. Higuchi T, Seki N, Kamizono S, Yamada A, Kimura A, Kato H and Itoh K: Polymorphism of the 5'-flanking region of the human tumor necrosis factor (TNF)-alpha gene in Japanese. Tissue Antigens 51: 605-612, 1998.

27. Barasch A and Peterson DE: Risk factors for ulcerative oral mucositis in cancer patients: Unanswered questions. Oral Oncol 39: 91-100, 2003.

28. Hensley ML, Hagerty KL, Kewalramani T, Green DM, Meropol NJ, Wasserman TH, Cohen GI, Emami B, Gradishar WJ, Mitchell RB, et al: American society of clinical oncology 2008 clinical practice guideline update: Use of chemotherapy and radiation therapy protectants. J Clin Oncol 27: 127-145, 2009.

29. Lalla RV, Bowen J, Barasch A, Elting L, Epstein J, Keefe DM, McGuire DB, Migliorati C, Nicolatou-Galitis O, Peterson DE, et al: MASCC/ISOO clinical practice guidelines for the management of mucositis secondary to cancer therapy. Cancer 120: 1453-1461, 2014.

30. Peterson DE, Boers-Doets CB, Bensadoun RJ and Herrstedt J; ESMO Guidelines Committe: Management of oral and gastrointestinal mucosal injury: ESMO clinical practice guidelines for diagnosis, treatment and follow-up. Ann Oncol (26 Suppl 5): v139-v151, 2015. 